\title{
Genetically engineered live-attenuated cytomegalovirus (CMV) vaccines improve pregnancy outcome in the guinea-pig model of congenital CMV infection
}

\author{
Mark R Schleiss ${ }^{* 1}$, Alistair McGregor ${ }^{1}$, Yeon Choi ${ }^{1}$, Jodi Anderson ${ }^{1}$, \\ Mike Leviton ${ }^{1}$, Xiaohong $\mathrm{Cui}^{2}$ and Michael McVoy ${ }^{2}$
}

\author{
Address: ${ }^{1}$ Center for Infectious Diseases and Microbiology Translational Research, Minneapolis, MN, USA and ${ }^{2}$ Medical College of Virginia and \\ Virginia Commonwealth University, Richmond, VA, USA \\ * Corresponding author
}

\begin{abstract}
from Fourth Dominique Dormont International Conference. Host-Pathogen Interactions in Chronic Infections Paris, France. 13-15 December 2007

Published: 9 April 2008

Retrovirology 2008, 5(Suppl I):P4 doi:I0.I 186/I742-4690-5-SI-P4
\end{abstract}

This abstract is available from: http://www.retrovirology.com/content/5/SI/P4

(c) 2008 Schleiss et al.; licensee BioMed Central Ltd.

\section{Background}

Congenital CMV infection is a major cause of disability in newborns. An effective preconception vaccine is a major public health priority. The guinea-pig cytomegalovirus (GPCMV) model was utilized to evaluate the efficacy of live, attenuated CMV vaccines generated using a bacterial artificial chromosome (BAC) approach.

\section{Methods}

The GPCMV genome was cloned as a BACmid in E. coli and used to regenerate a wild-type viral vaccine (wt), and a highly attenuated recombinant vaccine deleted of the gene encoding the dominant T-cell target, UL83 (pp65). Seronegative animals were immunized with a two-dose series of each vaccine ( 0 - and 3- week schedule), or placebo. Following establishment of pregnancy, dams were challenged with salivary gland-passaged (SG) GPCMV $\left(5 \times 10^{5} \mathrm{pfu}\right)$ in the second trimester, and pregnancy outcomes were compared.

\section{Results}

Vaccinated dams seroconverted to GPCMV antigen. ELISA titers were significantly higher in the wt $\left(2.8+/-0.3 \log _{10}\right)$ compared to the 409 group $\left(2.5+/-0.2 \log _{10} ; \mathrm{p}<0.05\right)$. Vaccination resulted in highly significant reductions in the magnitude and duration of DNAemia post-SG challenge, and was associated with improved pregnancy outcomes. Among 13 litters in the control group, there were
29 live and 22 dead pups (43\% mortality, mean pup weight of $89 \mathrm{~g})$, compared to 45 live and 14 dead pups born to 15 litters in the vaccine group (26\% mortality, mean pup weight $106 \mathrm{~g}$; $\mathrm{p}<0.05$ vs. control). The two vaccines were comparable in reducing GPCMV transmission at the placental and fetal levels.

\section{Conclusions}

Live, attenuated CMV vaccines are effective at preventing congenital infection and disease in the guinea pig model. Of interest, although UL83 is an effective subunit vaccine in guinea-pigs, immune responses to UL83 are not essential for fetal protection in the context of a live-virus vaccine. Recombinant CMV vaccines with targeted mutations of pathogenesis or immune evasion genes warrant further consideration in clinical trials. 